\title{
P0165
}

\section{ROAD LIGHTING MEASUREMENTS BY AN EQUIPPED VEHICLE}

\author{
Shau-Wei Hsu et al.
}

DOI 10.25039/x46.2019.PO165

from

CIE x046:2019

Proceedings

of the

29th CIE SESSION

Washington D.C., USA, June 14 - 22, 2019

(DOI 10.25039/x46.2019)

The paper has been presented at the 29th CIE Session, Washington D.C., USA, June 14-22, 2019. It has not been peer-reviewed by CIE.

(C) CIE 2019

All rights reserved. Unless otherwise specified, no part of this publication may be reproduced or utilized in any form or by any means, electronic or mechanical, including photocopying and microfilm, without permission in writing from CIE Central Bureau at the address below. Any mention of organizations or products does not imply endorsement by the CIE.

This paper is made available open access for individual use. However, in all other cases all rights are reserved unless explicit permission is sought from and given by the CIE.

CIE Central Bureau

Babenbergerstrasse 9

A-1010 Vienna

Austria

Tel.: +4317143187

e-mail: ciecb@cie.co.at

www.cie.co.at 


\title{
ROAD LIGHTING MEASUREMENTS BY AN EQUIPPED VEHICLE
}

\author{
Hsu, S.W., Chen, C.H., Hung, S.T., and Chung, T.Y. \\ Center for Measurement Standards, Industrial Technology Research Institute, Hsinchu, \\ CHINESE TAIPEI \\ SWHsu@itri.org.tw
}

DOI 10.25039/x46.2019.PO165

\begin{abstract}
New technologies have established with an equipped vehicle for rapid measurements of photometric quantities of long lighted roads. The measurement ranges of illuminance and luminance are $1 \sim 1000 \mathrm{~lx}$ and $0.1 \sim 100 \mathrm{~cd} / \mathrm{m}^{2}$, respectively. The resolution of the equipped vehicle is $0.3 \mathrm{~m}$, and the sampling distance is less than $2 \mathrm{~m}$. The matched results of illuminance distributions correspondingly measured by the new and conventional methods confirm the validity of this method.
\end{abstract}

Keywords: Road lighting, Measurement, Vehicle

\section{Introduction}

In our previous studies, as shown in Fig. 1, the on-site measurements of illuminance and luminance distributions on several LED-lighted roads had been carried out by semiautomatic systems and processes according to the CIE-140, CIE-194, and EN-13201 standards [1-4]. The long-period in-field measurements and analyses show that the performance of the tested LED road lightings meet the demand of M5-class highway in Taiwan. Some luminance parameters obtained from the ILMD are close to those from simulations and common luminance meters. Advanced luminance parameters should only be measured by ILMD. Almost all the illuminance parameters of the tested sections are fit with simulations. These results prove the validities of in-field measurements on LED road lighting, and their correspondences with simulations and other measuring devices.

Although the above experimental results are effective for the evaluations of the qualities of the roads, the speed of the measurements are somewhat slow, especially for the long and/or heavy-traffic roads. To improve the disadvantage, we have developed new measurement technologies based on an equipped vehicle. In this work, the measured illuminance and luminance data were converted to relatively more fundamental parameters and practical quantities with algorithms derived from theory of photometry [5].

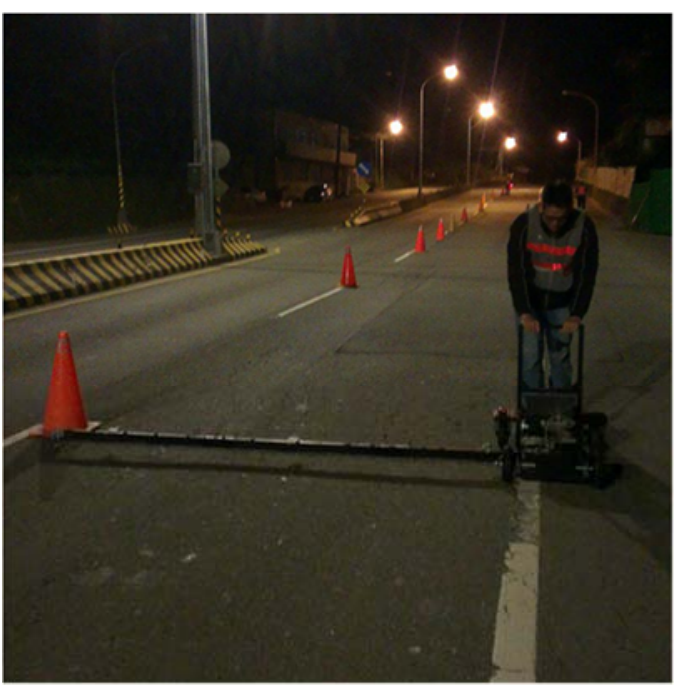

(a)

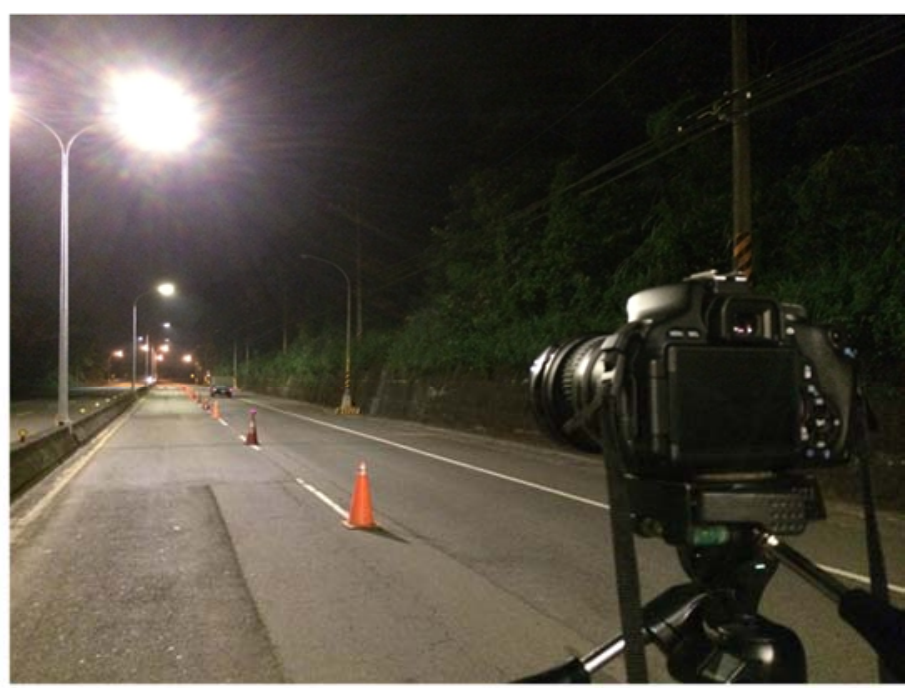

(b)

Figure 1 - Semiautomatic measurement systems. (a) illuminance; (b) luminance 


\section{Experiments}

As shown in Fig. 2, the equipped vehicle was built from a recreational vehicle by fixing a crossbar on the roof of the vehicle. Three sets of lux meters (labelled with $i=0,1$, and 2 ) were mounted on the crossbar with distance of $1.5 \mathrm{~m}$ between the sets. Four lux meters with directions of up, forward, left, and backward (labelled with a, b, c, and d, respectively) were integrated as the sets mentioned above.

An industrial camera was calibrated as an image luminance measuring device (ILMD) to measure luminance images of road. It is also mounted on the crossbar by an extended rod with length of $1.5 \mathrm{~m}$. Positioning of the vehicle was achieved by an encoder linked with rear axle shaft and an inertial measurement unit (IMU) mounted on the crossbar. The resolution of the equipped vehicle is evaluated as $0.3 \mathrm{~m}$, and the sampling distance is less than $2 \mathrm{~m}$. The connections between these modules are shown in Fig. 3, where a notebook is used for the automatic measurements. Fig. 4 shows the finished equipped vehicle.

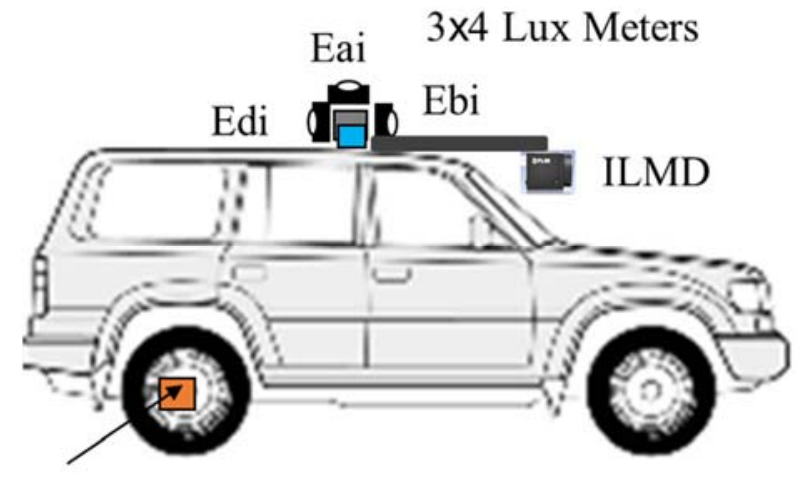

Encoder

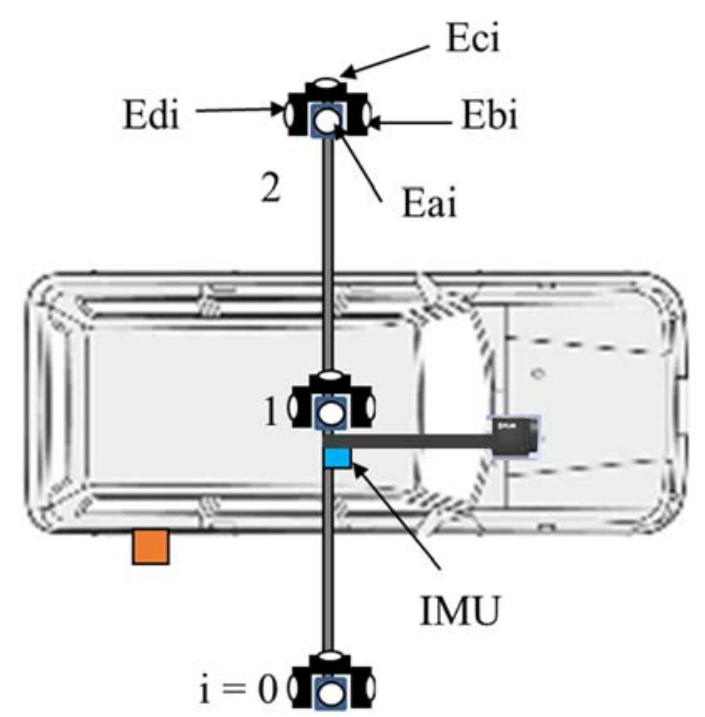

Figure 2 - Schematic diagram of the equipped vehicle, (a) Side view; (b) top view.

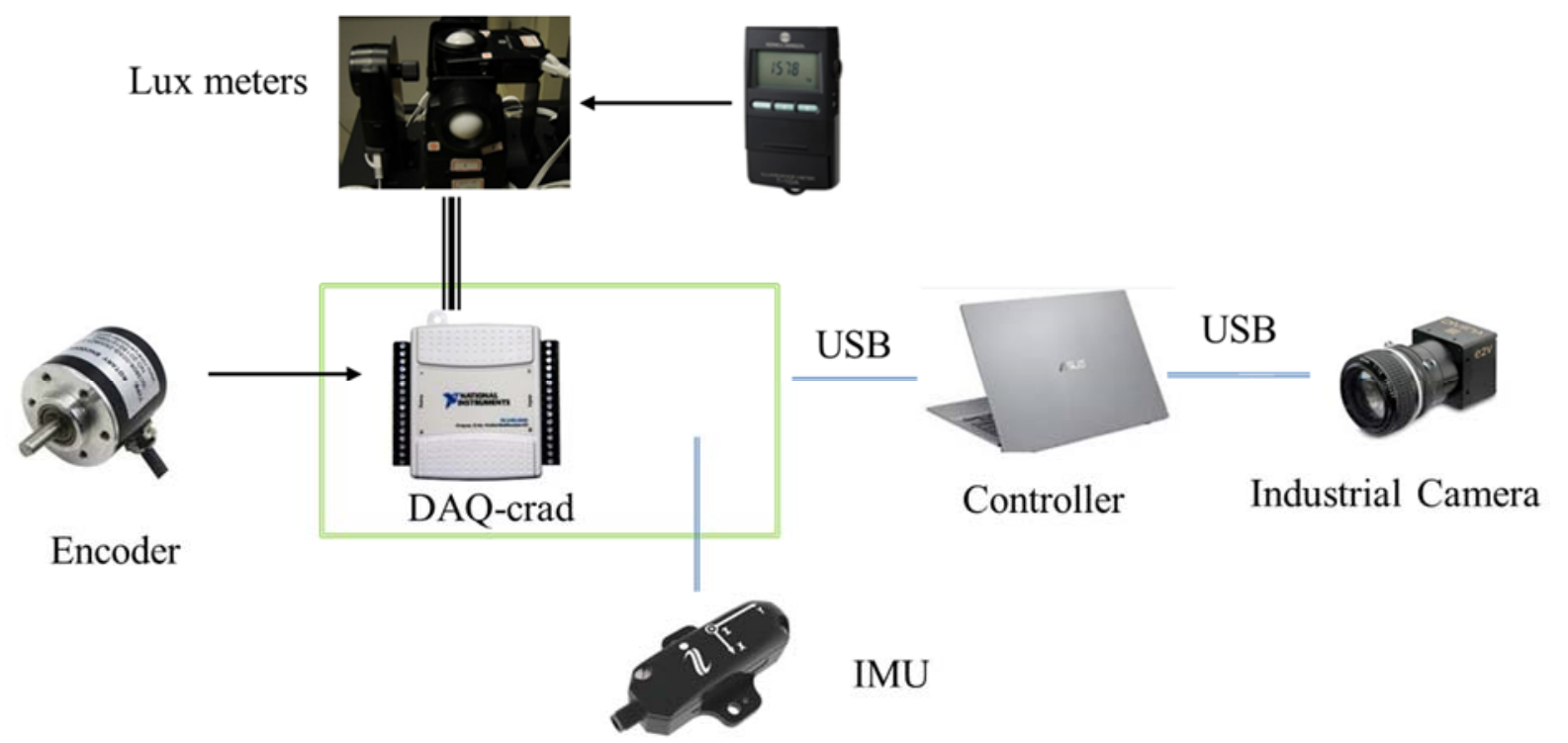

Figure 3 - Connections between the modules on the equipped vehicle. 


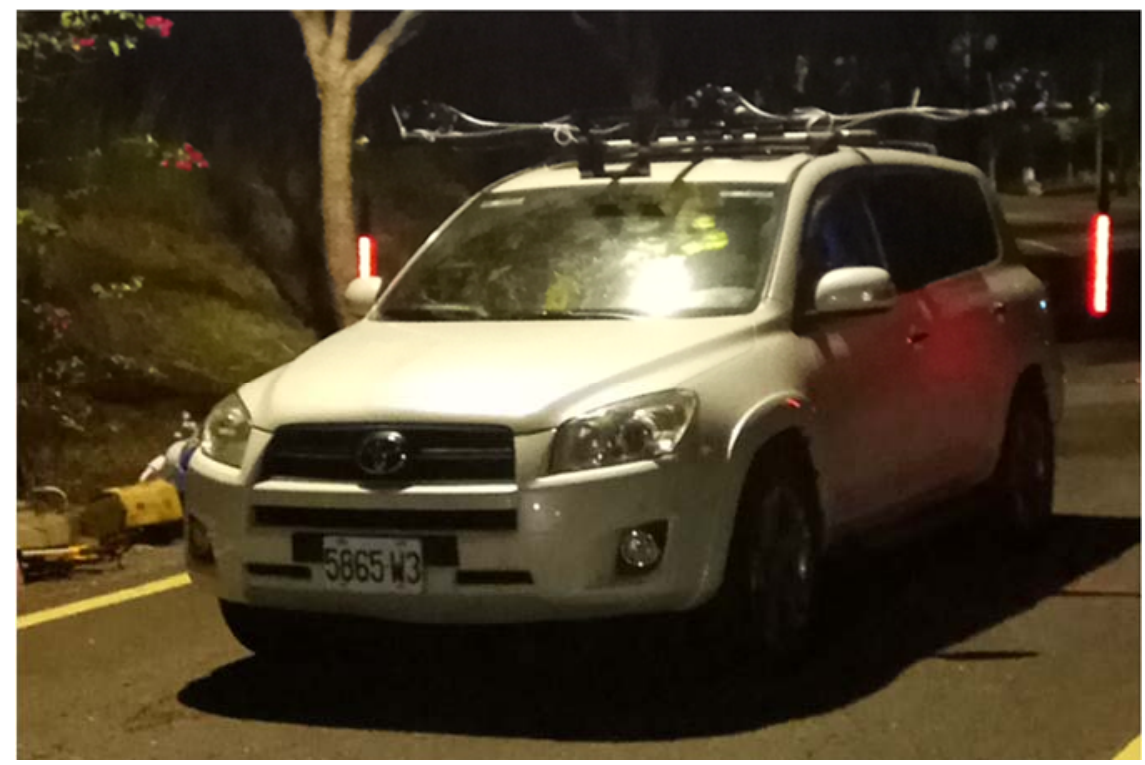

Figure 4 - Photograph of the equipped vehicle.

The measurement principle of illuminance by the equipped vehicle is illustrated in Fig. 5, where the vehicle is driven along a road with lightings at position $\vec{R}_{j}$. The illuminance recorded by a meter such as $E_{a i}$ can be expressed as

$$
E_{a i}=\sum \frac{I_{i j} \cdot \max \left[\hat{n}_{a} \cdot\left(\vec{R}_{j}-\vec{S}_{i}\right), 0\right]}{\left|\vec{R}_{j}-\vec{S}_{i}\right|^{3}}
$$

where $\vec{S}_{i}$ is the position of $i$-th set of lux meters, $I_{i j}$ is the luminous intensity from $\vec{R}_{j}$ to $\vec{S}_{i}$, and $\hat{n}_{a}$ is the normal vector of lux meter $A$ at $i$-th set. Along the road, the illuminances $E_{a i}, E_{b i}, E_{c i}$ and $E_{d i}$ can be measured as functions of $\vec{S}_{i}$. These parameters, as well as $\vec{R}_{j}$, are automatically recoded and calculated with the system shown in Fig. 3.

With lots of the above measured parameters, the distribution of luminous intensity $I_{i}\left(\frac{\vec{R}_{j}-\vec{S}_{i}}{\left|\vec{R}_{j}-\vec{S}_{i}\right|}\right)$ can be obtained by linear regression according to eq. (1). Software developed with Labview was used for the automatic measurements and analyses in this work. There are some parameters such as horizontal/vertical illuminance distribution, or flicker caused from nonuniformity can be calculated from the distributions of luminous intensity of the road lightings. Note that the above theories are generally suitable for curved or sloped road, and irregular layout of road lightings.

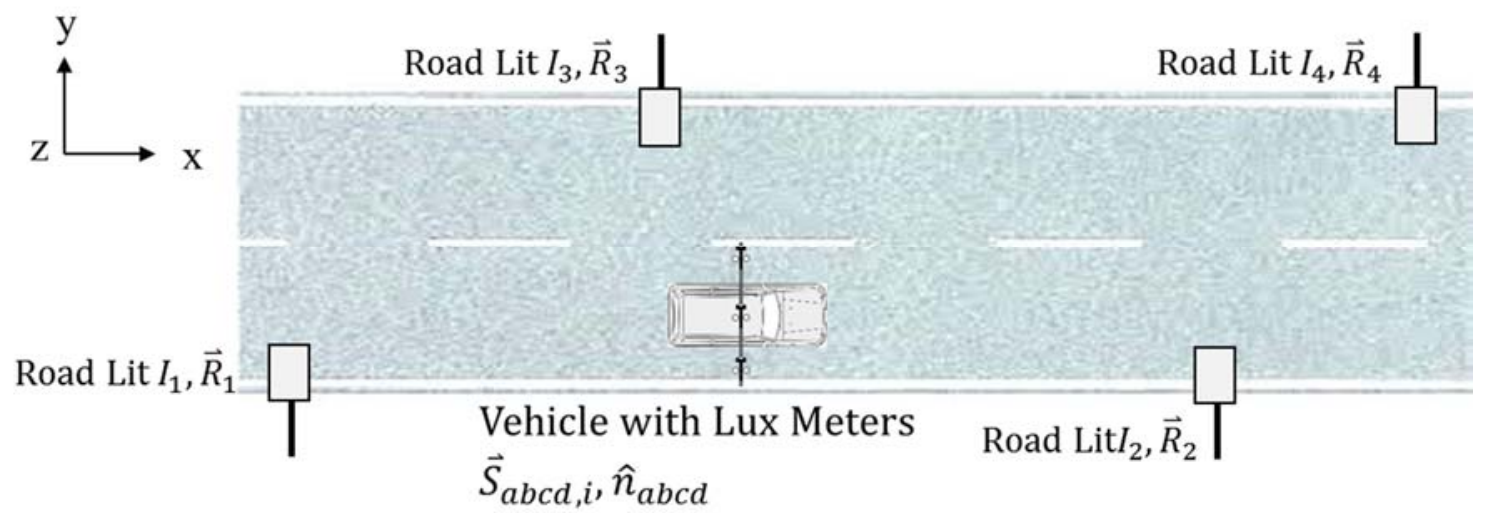

Figure 5 - Illustration of the vehicle at a lighted road. 
The luminance images along the road were captured with the ILMD. The position of ILMD corresponding to each image is also obtained from the encoder and IMU. Luminance distribution reflected from the road can be analysed by integration of technologies of the edge-finding algorithm, correction of perspective image, and sampling method on the luminance images [1,6-7]. The measurement ranges of illuminance and luminance were adjusted as $1 \sim 1000 \mathrm{~lx}$ and $0.1 \sim 100 \mathrm{~cd} / \mathrm{m}^{2}$, respectively.

\section{Results and Discussions}

As shown in Fig. 6, to test the performance of the equipped vehicle, a 2-lane road with width of $7.2 \mathrm{~m}$ and light poles with height of $7.4 \mathrm{~m}$ was measured. The speed of the vehicle is about $20 \mathrm{~km} / \mathrm{h}$. This road is slightly sloped and curved for testing the flexibility of the measurement systems. The sampling and measuring processes of the road were mainly referred to the related CIE and CEN EN standards [1-3].

Figure 7 shows the measured and recalculated horizontal illuminances $\left(\sim E_{a i}\right)$ at height of $2 \mathrm{~m}$. $R, C$ and $L$ in the figure denote crosswise distances from the edge of lane of $0.6 \mathrm{~m}, 1.8 \mathrm{~m}$, and $3.0 \mathrm{~m}$, respectively. By the method described in the previous section, the recorded distributions of illuminances $\left(E_{a i}, E_{b i}, E_{c i}\right.$ and $E_{d i}$ ) along the road were used to obtain the luminous intensity distributions of the road luminaires. It is found that the horizontal illuminances recalculated from the luminous intensity are matched with those by measured.

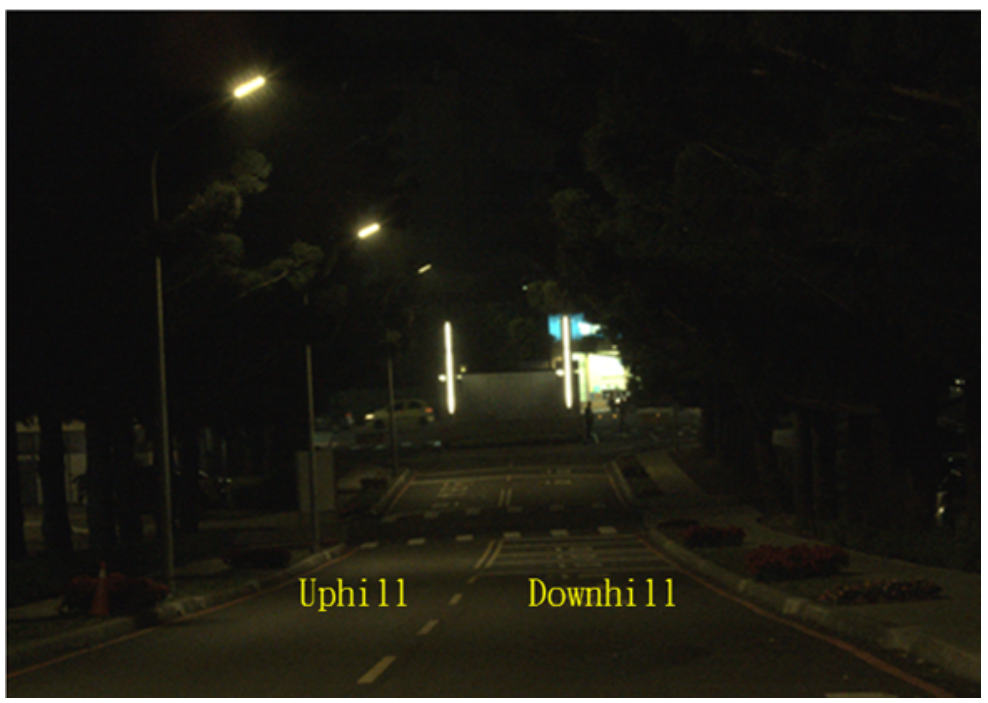

Figure 6 - A road for the experiments by the equipped vehicle.

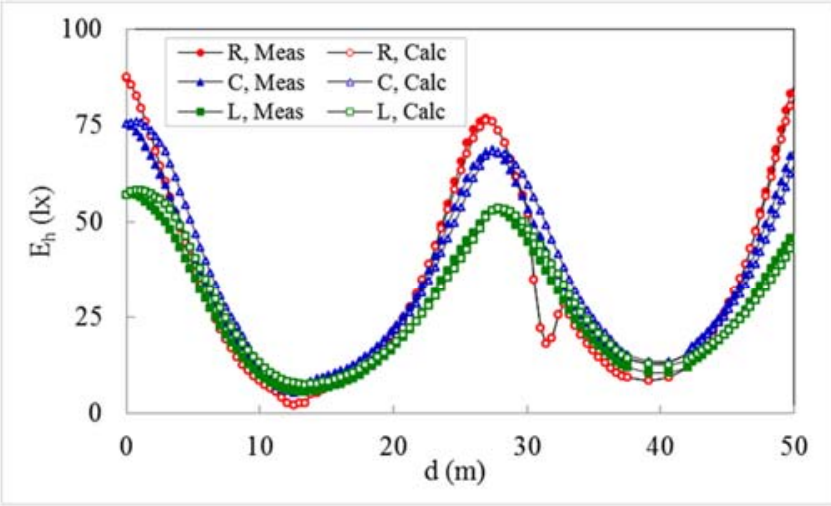

(a)

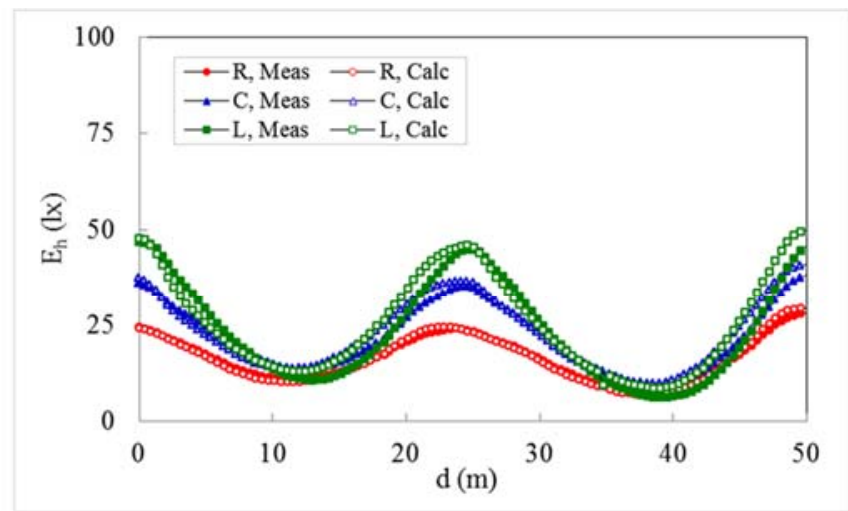

(b)

Figure 7 - Measured and recalculated horizontal illuminances at height of $2 \mathrm{~m}$. (a) uphill lane; (b) downhill lane. 


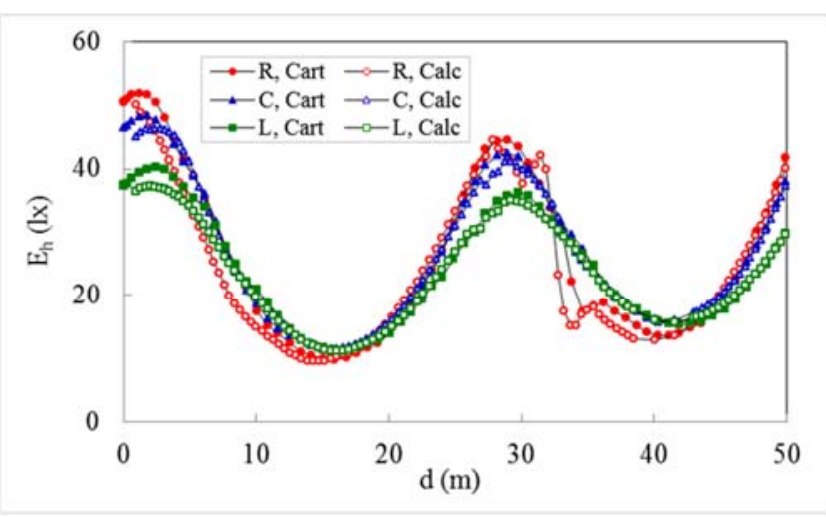

(a)

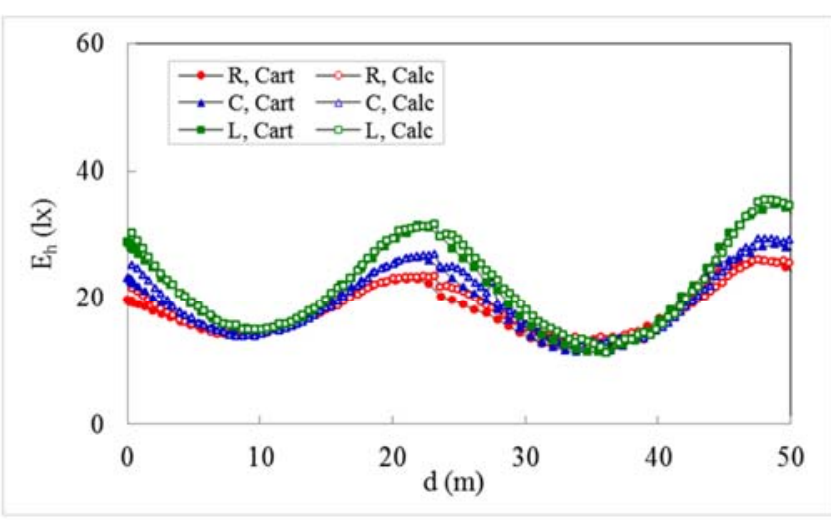

(b)

Figure 8 - Measured and calculated horizontal illuminances at height near ground. (a) uphill lane; (b) downhill lane.

As shown in Fig. 8, with the luminous intensity distributions, the horizontal luminance distributions near ground were calculated, and are close to those measured form the semiautomatic method (cart in Fig. 1(a)). The average illuminance and uniformity for the downhill case were calculated as $19.8 \mathrm{Ix}$ and 0.56 , which are close to $19.9 \mathrm{Ix}$ and 0.53 measured by the cart. Other practical quantities such as vertical illuminance distribution at specific height, and flicker caused from non-uniformity can also be calculated furthermore.

The luminance images were simultaneously captured as the illuminances recorded. According to speed of the vehicle of $20 \mathrm{~km} / \mathrm{h}$, the frame rate and shutter speed were set as $1 \mathrm{frame} / \mathrm{h}$ and $1 / 30 \mathrm{sec}$, respectively. Fig. 9(a) shows a typical uphill image, in which the sampling positions with acceptance angle of $0.1^{\circ}$ (yellow circles) were automatically determined with the method described in the previous section. The observation distance (S) between the ILMD and the nearest position in Fig. 9(a) is $20.6 \mathrm{~m}$.

From Fig. 9(a), the luminance as a function of sampling position can be obtained and are plotted in Fig. $9(\mathrm{~b})$. The average luminance ( $\mathrm{L}_{\text {ave }}$ ) and uniformity $\left(\mathrm{U}_{0}\right)$ at this observation distance are $1.14 \mathrm{~cd} / \mathrm{m}^{2}$ and 0.85 , respectively. For observation distance between $27.9 \mathrm{~m}$ and $44.5 \mathrm{~m}$, the images were similarly captured and processed. The luminances corresponding to the same sampling positions were obtained. The average luminance and uniformity as functions of observation distance are shown in Fig. 10(a) and (b), respectively. It is found that Lave is between 1.12 and $1.23 \mathrm{~cd} / \mathrm{m}^{2}$, and $\mathrm{U}_{0}$ is between 0.76 and 0.86 . That means the variation of the reflected luminance is small of this lighted road.

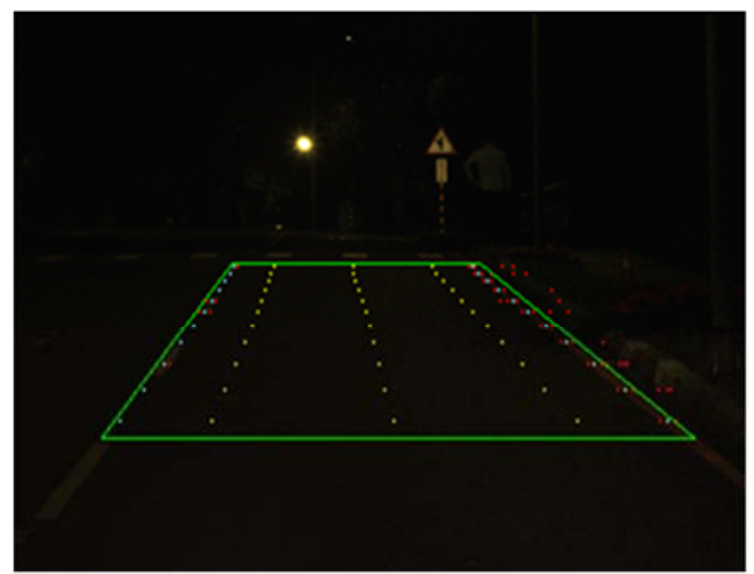

(a)

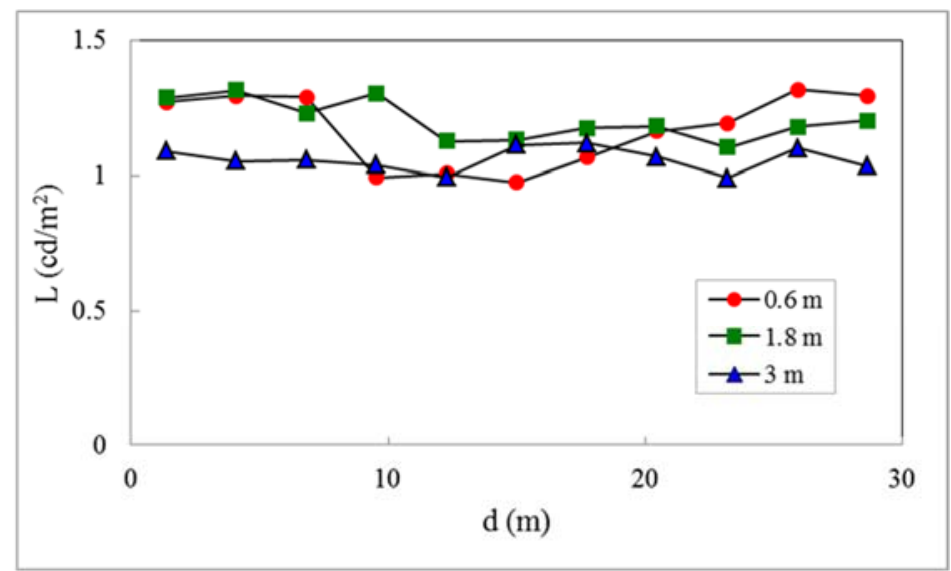

(b)

Figure 9 - (a) A typical uphill image; (b) Luminance as a function of sampling position. 


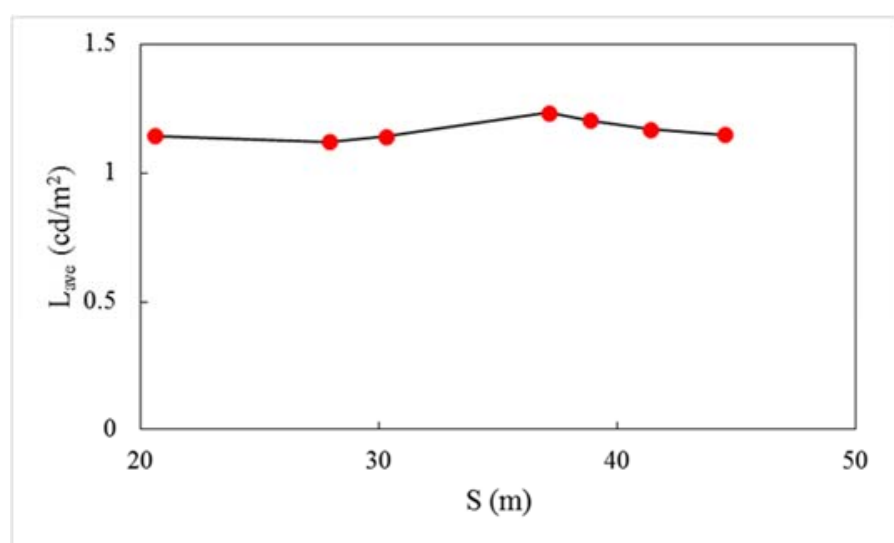

(a)

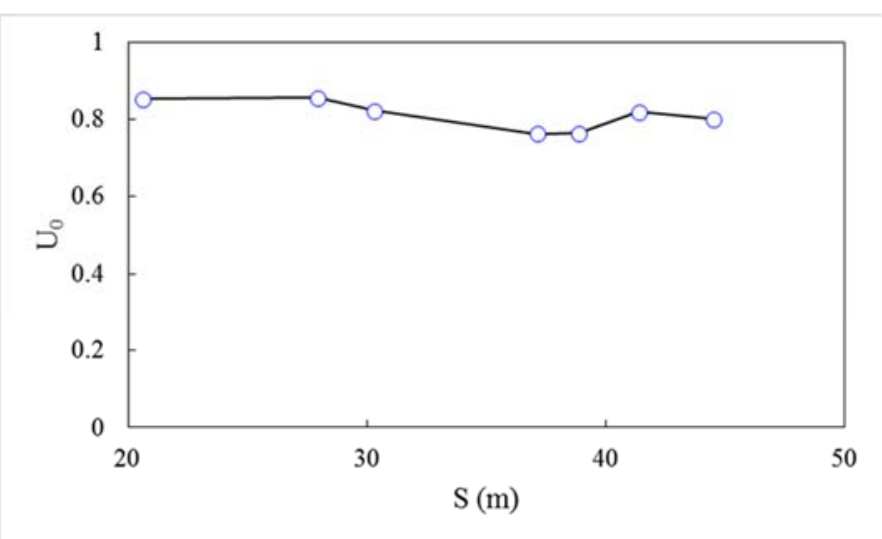

(b)

Figure 10 - (a) average luminance; (b) uniformity as functions of observation distance.

\section{Conclusions}

An equipped vehicle has been developed for rapid measurements of illuminance and luminance distribution along the lighted road. The experiment results of illuminance and luminance measurements between those obtained by this and conventional methods are competed. It is expected this method would provide a contribution for the rapid measurements and evaluations of long lighted roads.

\section{References}

[1] CIE 140: 2000: Road lighting calculations. Vienna: CIE, 2000.

[2] CIE 194: 2011: On site measurement of the photometric properties of road and tunnel lighting. Vienna: CIE, 2011.

[3] CEN EN 13201-4: 2003: Road lighting - Part 4: Methods of measuring lighting performance. Brussels: CEN, 2003.

[4] Hsu, S.W., Wu, K.N. and Hung, S.T., 2015. Performance of LED road lightings studied by detailed in-field measurements with various devices. Proceedings of CIE 2015.

[5] CIE 121: 1996: The photometry and goniophotometry of luminaires. Vienna: CIE, 1996.

[6] Kim, Z.W., 2008. Robust lane detection and tracking in challenging scenarios", IEEE Trans. Intelligent Transportation Systems 9, 16.

[7] Tong, L.L. and Zhang, Y, 2010. Correction of perspective text image based on gradient method, IEEE International Conference on Information, V2-3I2. 